\title{
Dialectics between Splitting and Integrating in the Lives of Heterosexually Married Gay Men
}

\author{
Adital Ben-Ari, Adir Adler \\ School of Social Work University of Haifa, Haifa, Israel. \\ Email: \{mselizur, mseba\}@mscc.huji.ac.il, darja.zavirsek@fsd.uni-lj.si \\ Received February $26^{\text {th }}, 2010$; revised April 16 ${ }^{\text {th }}, 2010$; accepted April $18^{\text {th }}, 2010$.
}

\begin{abstract}
Mixed-orientation marriage is usually an invisible phenomenon, but its frequency is not insignificant. The present paper describes and examines the experiences of 13 heterosexually married gay men, seven of whose wives were aware and six who were unaware of their husbands' homosexuality. We take the insiders' perspective as a point of departure to develop a conceptual model that may contribute to our understanding of the constructed reality of this relatively unexplored phenomenon. The findings show that life in a mixed-orientation marriage can be understood along a continuum running between two poles: splitting and integrating. This continuum corresponds to the fundamental question in the lives of heterosexually married gay men: Is integration between homosexuality and heterosexual marriage possible, and if so, how?
\end{abstract}

Keywords: Qualitative Research, Mixed-Orientation Marriage, Disclosure, Gay Men, Integrating, Splitting

\section{Introduction}

The Mixed-orientation marriage is usually an invisible phenomenon, but its frequency is not insignificant. No accurate estimate of the prevalence of heterosexually married gay men is available in the literature [1]. Kinsey [2] estimated that $1.7-1.9 \%$ of heterosexually married men are homosexuals. A survey using a probability sample of gay males found that $42 \%$ of the men who selfidentified as homosexuals or bisexuals had previously been married to a woman [3]. Other studies show that $20 \%$ of homosexuals had been married to a woman at some point in their lives [4-6]. A more recent study [7] shows that an estimated two million homosexuals, lesbians and bisexuals in the US had, at some time in their lives, been part of a mixed-orientation marriage.

What brings a homosexual man to marry a woman? The literature suggests a number of explanations includeing internal homophobia [8], cultural and social expectations [3-5,9], social and familial pressure, a wish to hide or eliminate the sexual orientation, desire to have children, feelings of love towards the woman, dissatisfaction with the homosexual world and negative feelings towards the homosexual lifestyle [10-12]. This array of motives is dynamic in that it may change over time. For example, Matteson [13] has distinguished between positive and negative motives, corresponding to the periods prior to and following the Stonewall Riots in 1969. These violent riots took place between policemen and homosexuals, lesbians and transsexuals at Greenwich Village, New York. This event marks the establishment of the gay rights movement in the US and around the world. Matteson found that the most common motive for gay man to marry a woman prior to this incident was the negative perceptions of homosexuality, and following the event, it was the desire for family life.

In principal, mixed-orientation marriage can take one of two forms; the wife is either aware or unaware of her husband's homosexuality [12-14]. Within this context, the present paper examined personal narratives of gay men who were married to women, some of who were aware and some who were unaware of their husbands' homosexuality, to gain a deeper theoretical understanding of mixed-orientation marriages. It is important to note that the nature of unawareness is dynamic and it may evolve over time (i.e. a woman can become aware of the man's sexual orientation in different stages of the marriage).

Gay men's heterosexual marriages are usually portrayed as problematic [8,11,14-15]. In an attempt to provide an answer to the question of why mixe-dorientation marriages break apart, Higgins [8] referred to cognitive consistency theory. According to this theory, a cognitive dissonance occurs when one's behavior is inconsistent with one's perception of it. In the case of mixedorienttion marriages, a dissonance exists between homosexual 
men's attraction to members of their own sex, and their engagement in heterosexual marriages. The cognitive dissonance increases as the man manages two simultaneous relationship systems with a woman and with men, thereby running a double life. In order to obtain consistency, these men make the decision to marry (i.e., invoking the belief that homosexuality is wrong, homosexual relationships are doomed to fail, etc.). To attain congruence in this situation, homosexual men may disclose their sexual orientation, identifying with and participating in the homosexual world [16].

As mentioned, researchers have been aware of the fundamental difference between the two situations in which women are aware or unaware of their husbands' homosexuality [12-14]. Each of these two situations involves certain individual and dyadic processes, which will be examined below.

\subsection{Wives are Unaware of their Husbands' Homosexuality}

Little has been written about this specific phenomenon. Berger [10] found that although successful marriages of this type are rare, several men reported having satisfying marital relationships. Their wives' and children's lack of awareness is a mediator variable that contributes to the perception of the marriage as successful. The gay men's concealment appears to play an essential role. However, Binger [14] indicates that many of these men are likely to experience guilt and anxiety. Guilt stems from their unauthentic lifestyle and from the concealment itself. Anxiety is associated with the potential harmful ramifications of an unplanned discovery of their homosexuality.

Several theoretical perspectives have been suggested to account for the implications of concealment by heterosexually married gay men. Pennebaker $[17,18]$ suggested that Inhibition Theory may provide a useful explanation, as it emphasizes conflict or inhibition over emotional expression (e.g. concealment), which may result in stress-related illnesses or reactions. According to this theory, emotional expression and sharing significant personal aspects with others via disclosure are important to maintaining good mental and physical health. Using a Minority Stress conceptual framework, Meyer [19] concluded that the combination of various stress-simulating processes, such as concealment of sexual orientation, can provoke mental health problems. In conclusion, concealment of sexual orientation can have destructive implications for homosexual men, both emotionally and physically. Interestingly, while the wife's unawareness appears to be a contributing factor to the success of the marriage, the concealment of homosexuality is thought to be a disruptive factor.

\subsection{Wives are Aware of their Husbands' Homosexuality}

Relatively more scholarly attention has been directed to couples who share the information about the husbands' homosexuality, particularly in the 1980's [11-13]. Disclosure of homosexuality to wives varies and may occur during different stages of the marital relationship: Some men come out prior to the marriage, while others do so during their married lives, which may pose a certain threat to the continuation of the marriage. Both spouses can find themselves in situations where they would initiate termination of their relationships. Even for those who decide to keep their marriage intact, homosexuality can be a source of tension and conflict, introducing continuous pessimism about the future of their marriage [11,12]. In spite of such complexities, some couples manage to sustain their marriage following the discovery of the husband's homosexuality. In these cases, the spouses begin to integrate homosexuality into their heterosexual relationships [12]. Several studies have indicated that some couples indeed survived the crisis following disclosure $[13,20]$, emphasizing that open communication, understanding and acceptance of homosexuality by both spouses can help the couple overcome their difficulties [12].

Couples in mixed-orientation marriages cope with the complexity of the situation in various ways, including various networks of social support (homosexual, heterosexual and bisexual); professional help or paraprofessional support groups (self-help groups for other men and couples in a similar situation). At the dyadic level, couples develop various accepted rules or routines related specifically to the husband's homosexual behavior and practices, e.g. the husband always comes home at night, takes precautions against infectious diseases, limits his sexual partners, etc. [12]. Successful adaptation to mixed-orientation marriage has been attributed to several factors. One is love and affection between spouses, together with their commitment and desire to maintain a successful relationship. Another is open communication and physical contact, as well as dealing with feelings of guilt and shame related to the husband's sexual orientation. Allowing the wife's sense of self-realization outside the marriage as well as agreeing upon practices related to the husband's homosexual encounters may also contribute to successful adaptation. This can include the creation of a contract between the spouses on such issues; for example, establishing that the woman would not be informed about the husband's sexual contacts, deciding to conduct an open relationship, etc. [11]. In addition, the husband's realization of his homosexuality was found to contribute to the quality and stability of the marital relationships [21].

Most of the literature about mixed-orientation marriages was written during the 1980's and referred to quantitative studies. The present study, however, utilizes qualitative methodology and examines constructed meanings and experiences of heterosexually married gay men [22], with wives who are aware and unaware of their homo- 
sexuality. We take the insiders' perspective as a point of departure to develop a theoretical framework that may expand our understanding of the constructed reality of this relatively unexplored phenomenon [23]. Within this perspective, the main research question is as follows: Is integration between homosexuality and heterosexual marriage possible, and if so, how? Is there an alternative way in which a homosexual man can realize his sexual orientation and simultaneously live in a heterosexual marriage?

\section{Method}

\subsection{Participants}

The participants were 13 heterosexually married men, who define themselves as "gay". Seven of the wives were aware of their husband's homosexuality and six were unaware. One man had disclosed his sexual orientation to his wife before the marriage, while the other six had made the disclosure at different stages of the marriage. The men's average age was 51 years $(S D=8.43$ ), ranging from 35-64 years old. The average duration of marriage was 24 years $(S D=9)$, ranging from five to 37 years of marriage. All the married couples had children, and all participants were secular Jews with high school or academic education.

The participants were recruited using criterion sampling, to ensure their compatibility with the phenomenon under study [22]. We interviewed gay men whose wives were aware of their homosexuality, as well as those whose wives were unaware, to increase variation within the studied phenomenon. In addition, we located participants of different ages and at different stages of married life. This line of reasoning was based on the assumption that any common patterns emerging as a result of greater variation would be valuable in capturing the core experiences [24]. The sampling process ended when theoretical saturation was reached, when new information from the participants fit existing themes, but did not add new categories of meaning [25].

\subsection{Procedure}

Participants were recruited through a dating website for the homosexual community, according to the criteria specified above. Out of more than 125 men who were contacted, 99 did not respond, 20 responded but refused to be interviewed due to fear of exposure, and only six were willing to participate (four in the WN [wives unaware] group and two in the WA [wives aware] group). The other seven participants were recruited through snowball procedures and by word of mouth. Initial phone calls were conducted with each participant, in which research description, interview processes, documentation methods and procedures to ensure confidentiality were presented, followed by participants' consent to be inter- viewed. Then, a face-to-face interview was scheduled. Time and place were determined by participants' preferences. Each interview lasted between one and two hours. The interviews were digitally audiotaped. In addition to ensuring accuracy, this also enabled the researcher to be more attentive to the interviewee [24].

\subsubsection{Data Collection and Analysis}

Data was collected using in-depth semi-structured interviews focusing on the subjective experiences and perspectives of the heterosexually married gay men. The interview followed an interview guide containing a list of issues relevant to understanding the phenomenon [24]. Two versions of interview guide were developed, to meet the special issues characterizing each of the two situations of the studied phenomenon (i.e. WA and WN). The main questions in the first version dealt with issues including married life, relationships between the spouses, coping strategies, realization of husband's homosexuality and disclosure of homosexuality to the wife with regard to two time periods: prior to and following disclosure. The second version contained questions that related to the same issues as in the first version, but with no reference to the two time periods. Demographic data were collected uniformly in both versions (e.g. age, religiosity, education, etc.).

Data analysis was performed in several stages. First, all recorded interviews were transcribed verbatim and read as text to gain familiarity, bracketing prior perceptions and knowledge [24,26]. Second, a separate case analysis of each interview was performed to identify units of meaning related to the studied phenomenon, which were organized in meaningful clusters. Third, cross-case analysis was conducted, using an imaginative variation to find possible meanings and to approach the phenomena from several perspectives [26]. Fourth, structural synthesis was established, to reveal the essence of the phenomena and to develop a theoretical framework for more in-depth understanding [24].

\subsubsection{Trustworthiness and Credibility}

Unlike the positivist researcher who seeks for internal and external validity, the qualitative researcher is geared towards trustworthiness of findings and analysis [25]. Accepting that there is no single objective reality, the researcher is concerned with credibility, transferability, dependability and conformability [23]. In the present study, we employed the following procedures to establish trustworthiness. We used information-rich quotations to provide thick descriptions of various aspects of the studied phenomenon. An experienced researcher was closely involved in the analysis and interpretation of findings, which were then shared with some participants to receive their perception of the findings, including suggested meanings and interpretations [25]. 


\subsection{Results}

The interview data shows that life in a mixedorientation marriage can be understood along a continuum running between two poles: splitting and integrating. This continuum corresponds to the fundamental question in the lives of heterosexually married gay men: Is integration between homosexuality and heterosexual marriage possible, and if so, how? When telling their stories as homosexual married men, participants used contradictory terms to describe their experiences, which indicated mechanisms of splitting and integrating. In particular, they were attempting to create a separation between their homosexual life and their family life, while apparently integrating or wishing to integrate the two worlds simultaneously.

\subsubsection{Splitting in the Lives of Heterosexually Married Gay Men}

When splitting appears as the dominant theme in their stories, interviewees refer to their double lives in a dichotomous manner, using contradictory language. Such structural aspects may reflect their initial stance: that the two worlds cannot coexist in harmony. This means that only a total split between them would enable them to continue living in both worlds. Thus, splitting appears to be an essential mechanism contributing to the continuation of the heterosexual relationship. Within this context, splitting can be experienced at three related, often overlapping levels: emotional, cognitive and behavioral.

Emotional splitting: All participants perceived their relationships with their wives as essentially different from their relationships with men. Emotional splitting occurs when one relationship system, mostly with the woman, is characterized as emotional, while the other, mostly with the men, is not. Michael, who had been married for 25 years to a wife who was aware of his sexual orientation, used different words to characterize the two relationship systems. Excitement referred to relationships with men, while emotions defined the essence of his relationship with his wife:

Relationships with men mean excitement. After you have your orgasm, you put on your clothes and that's it, "back to reality." Reality is home, family, kids. Relationships with men are nothing but fantasy fulfillment. I'm very satisfied with my relationships with men. I mean the sex part, the sexual attraction and that's it. Sweating, preying, like an animal. Animals are like that. My relationship with my wife includes lots of emotion; love and appreciation.

By creating a contradiction between relationships with his wife and with men, between reality and fantasy, Michael used splitting as an enabling mechanism. By defining his homosexual relationships as fantasy, he was separating them from reality. After the fantasy was fulfilled, he returned to reality-his routine family life. He used metaphors from the animal world (e.g., sweating, preying) to describe his sexual encounters with men, which may also intensify the split between his homosexual life and his family life, as "preying" belongs to the fantasy. Thus, splitting allows for the movement between the two worlds, which helps to keep both intact. It would appear that only one relationship system is generally defined as emotional, meaning that love and affection tend to be directed toward only one intimate partner in one relationship system. This can be either a man or a woman, but not both.

Cognitive splitting manifests itself in various ways, including in the minimization of homosexuality and its significance; viewing homosexuality as a temporary phase, as a transient episode; or objectification of the sexual orientation. Daniel, who had been married to his wife for 20 years and discovered his homosexuality five years prior to the interview, used all of these in his narrative:

I hope it will end at some point. I want to continue with my normal life, because that is the most important thing in my life. As long as I have control over it and can maybe even stop it, I think it will go away. I feel good at the moment. Stop now? No, no, no! I'm enjoying my new toy very much. It's as though I've found a new toy. I play with it. I think that someday, I will have had enough of it-I really hope and believe so. I know myself. Throughout the whole of my life, I have had this tendency to get fed up of things and move on to something else. A few years ago, I suddenly had a passion for learning to play the organ. I bought an expensive organ and contacted a teacher. After only one lesson, I felt that it was enough and I stopped....I know that someday, my thing with men will also become a statue.

By objectifying his sexual orientation (i.e., a toy/organ/statue) and defining it as a temporary episode, Daniel actually distinguished between "doing" and "being" without creating a contingency between the two. Contrasting normalcy with playing served to gain a sense of control, allowing him to decide whether or not it was a part of him. This cognitive split served to normalize his life situation and to generate a feeling of stability and security. The two lives were not symmetrical: the heterosexual life was considered as "normal” and received the highest priority. His "thing with men” was just a passing hobby, implying that homosexuality is temporal, insignificant; an object whose excitement will eventually diminish.

Behavioral splitting: Several indications of behavioral splitting were identified in the interviews: limiting the homosexual encounter to an alienated meeting place and treating it as such; defining the encounter as a merely sexual act; washing the body carefully after the sexual encounter and before returning to the normalcy of the heterosexual relationship. All these contribute to the perception of the homosexual encounter as detached from anything in the familiar world. David, whose wife was 
unaware of his homosexual orientation, described such encounters as follows:

At that moment, I go down the stairs (after a sexual encounter with another man. If our paths cross, I will ignore him. I am not there any more. It is important for me to make a cut. I must separate and I know how to do that, because otherwise, you might get divorced. I will come home, take a good shower and wash everything away...I am clean again.

David had developed certain behavioral rituals to establish his much needed total separation in order to continue with his heterosexual life. At the end of the meeting, the man would leave the place and would totally ignore his male partner, expressing a conscious decision to renounce familiarity with the other man to prevent any continuation of the encounter. Thus, homosexuality was constructed as a merely sexual act, confined to a specific rendezvous, and not as an intimate relationship. This limited construction portrays homosexuality as insignificant, thereby protecting the heterosexual relationship. Indeed, some participants mentioned customarily washing their bodies after homosexual encounters. The apparently physical-behavioral act of washing signified a transition between the two worlds, which simultaneously intensified the split between homosexuality and the routine heterosexual life. Thus, the parallel emotional, cognitive and behavioral splitting enabled participants to lead a double life, and to continue living in both worlds while keeping each world intact.

\subsubsection{Integration in the Lives of Heterosexually Married Gay Men}

Although splitting was a more prevalent theme in the stories recounted by heterosexually married gay men, few participants spoke of integration between the two worlds. Integration is perceived as a desired ideal, a situation in which one does not have to relinquish either world. Such a perception challenges the dichotomous normative notion that homosexuals cannot be heterosexually married. Arik, who had been married for 25 years, described a period in which he felt good, because of the balance between the homosexual and the heterosexual aspects of his life:

Back in those days, I experienced a "modus Vivendi" in my life. I had my family, my wife, the good life I had with her in our home... and I was a very happy person. During those years, when I had Gil (a male partner), there was some kind of a balance, a feeling of serenity.

Running two parallel, long-term, stable relationship systems - one with the wife and one with another man - was perceived as an ideal, and therefore as a rewarding experience, as the ideal was realized as a possible alternative. Despite their satisfactory relationships with their wives and their love towards them, some interviewees reported the need for a simultaneous, committed, longterm, stable relationship with a man. Some participants expressed the potential for harmony and coexistence between the two worlds. Realization of one relationship system did not necessarily preclude the continuation of the other. If integration is possible, then splitting is no longer needed, and integration then replaces it.

Our relationship has been best since we got married, but I am still looking for a male partner, one who will accept the fact that I have a very good relationship with my wife that I do not want to break. We (he and his wife) had 25 good years, with ups and downs and we have a very long joint history, which isn't easy to give up. At the same time, I also need a relationship with a man, and I am not talking about casual sex, it's not enough. I need more (Daniel).

Daniel represents a desire voiced by several participants, to conduct two simultaneous, committed, stable relationship systems with a man and with his wife, which are viewed as complementary, creating balanced integration between the two worlds. Unlike the situations of splitting, where participants talked about integration, the homosexual and heterosexual relationship systems were not constructed as essentially different and contradictory, but as complementary. Within this context, it is noteworthy that participants described both the heterosexual relationship and their homosexual sexual encounters as relationship systems, suggesting a perceived implicit similarity between the two.

Although the two mechanisms - splitting and integrating-were presented in a dichotomous manner for heuristic purposes, they are, in fact, dynamic and tend to operate together, often in parallel. For example, a participant might describe in one interview how he detached himself emotionally from relationships with men and then express his yearning to manage two intimate relationships simultaneously, with his wife and with another man.

\section{Discussion}

Splitting and integrating are interwoven in participants' narratives. Some made a total split between their homosexual and heterosexual relationships; others integrated or wished to integrate the two worlds, and several men spoke in terms of both splitting and integrating. As such, the findings of the present study address the main research question: Can heterosexual and homosexual relationship systems coexist? Is there an alternative way in which homosexual men can fulfill their homosexuality and simultaneously engage in heterosexual marriages?

Leading two fully committed relationship systems with a man and a woman simultaneously, which are characterized as both emotional and sexual, contradicts mainstream Western cultures regarding the nature of intimate relationships [27]. This challenges the ideal of monogamist relationships and the binary structures of man/ woman and homosexual/heterosexual [28].

Although most of the literature is pessimistic about the 
success of mixed-orientation marriage [8,11,14,15], the findings of this study corroborate findings from several previous studies [12,13], suggesting that such relationship systems are not doomed to failure. In line with this, the concept of polyamory $[29,30]$ may be useful in providing ways to examine dominant mainstream relationship structures, as it undermines the monogamist relationship ideal and the concept that a relationship should exist between two people only. According to this approach, one can co- nduct sexual and/or emotional relationships with a number of people of the same or opposite gender. Although the literature about polyamory relates mainly to bisexual [31] and homosexual [32] couples, we argue that it may also be appropriate for mixed-orientation couples. As we accept the possibility of creating such a relationship system, and as our findings indicate that some participants wished to integrate the two worlds, we suggest an alternative conceptual model for their integration. Based on quantitative methodology, a previous theoretical model [13] suggested developmental stages in mixed-orientation marriages. In contrast to this, our model developed from the subjective experiences of heterosexually married gay men, together with their constructed meanings. Whenever relevant, it integrates accumulated knowledge pertaining to the studied phenomenon, to map the essential components that may contribute to the success of such marriages.

\subsection{Integrating Homosexuality within Heterosexual Marriage: A Conceptual Model}

1) Honesty and openness between the couple-When a couple decides to lead a one-sided or two-sided open relationship, honesty is an essential component [33]. The wife's awareness of her husband's homosexuality is an important part of such integration. The findings of the present study and the literature show that context [34] and timing [13] of disclosure of homosexual orientation can contribute significantly to relationship quality. Therefore, early disclosure of the sexual orientation within a positive context (e.g. to be open and increase intimacy in the relationship) can help both partners to adjust more successfully to the new situation.

2) Formation of a contract-Open communication may serve as the basis for an agreed upon contract related to the husband's homosexual practice outside the marriage $[11,20]$. The contract needs to be clear and dynamic to suit both partners' preferences. Issues that need negotiation include, for example, timing and location of homosexual encounters; what kind of information is disclosed vis-à-vis the homosexual encounters; the nature of the homosexual relations-emotional, physical, or both, long-term vs. temporal relationships, etc.

3) Acceptance of the sexual orientation-Acceptance of homosexuality by both partners is necessary for integration of the sexual orientation into the marriage $[7,11]$.
4) Fulfillment of the sexual orientation-Another important element in the integration process is the husband's fulfillment of his sexual orientation. The findings of our study show that sense of fulfillment can also project positively on the relationship with the wife. Some of the men returned home after homosexual encounters and felt they had more to give to their wives, both emotionally and physically. Previous research has also suggested that gratification from homosexual relations and a sense of fulfillment contributes to marital satisfaction [21].

5) Solid basis of the heterosexual relationship-After years of married life, participants who emphasized that love for their wives had been their main motive for marriage felt that they had established a solid relationship, which served as a good basis for the integration.

6) Perception of the mixed-orientation marriage as a unique alternative-Some of the participants in our study perceived heterosexual relationships as normative-_like any other normal heterosexual relationship." As this perception ignores the idiosyncratic components of mixedorientation marriage, it may cause difficulty in integrating the sexual orientation into the heterosexual marriage. Recognizing that this relationship creates a unique alternative and the understanding that it contains specific issues that are outside of mainstream conventional marriage is an empowering experience, which contributes significantly to successful integration.

We claim that the proposed model offers an alternative for those who decide to keep their marriage intact. We recognize that the model entails some challenging tasks facing the spouses on the personal and dyadic levels, including acceptance of the sexual orientation by both partners, agreement to a non-monogamist relationship system, openness, honesty, etc. This model originated from subjective experiences and meanings of individuals who were living the studied phenomenon, together with knowledge available from theory and research. Thus, it may contribute to our understanding of the constructed reality of gay people who attempt to integrate homosexuality into their heterosexual marriages. Such understanding could be used to help both men and women who are engaged in heterosexual marriages with gay men, as well as professionals working with such couples.

It is important to stress a salient limitation of the current study. Although we have focused on the mens' point of view, this multifaceted phenomenon needs to undergo a broader investigation by taking into account the perspectives of all the individuals involved in the situation, including: the woman, children and male partner if such exists. This deficiency is being addressed in a study we are conducting at the moment.

\section{REFERENCES}

[1] M. A. Yarhouse, L. M. Pawlowski and E. S. N. Tan, "Intact Marriages in Which one Partner Disidentifies with 
Experiences of Same-Sex Attraction," The American Journal of Family Therapy, Vol. 31, No. 5, 2003, pp. 375-394.

[2] A. C. Kinsey, W. B. Promeroy and C. E. Martin, "Sexual Behavior in the Human Male," Saunders, Philadelphia, 1948.

[3] J. Harry, “A Probability Sample of Gay Males,” Journal of Homosexuality, Vol. 19, No. 1, 1990, pp. 89-104.

[4] A. P. Buxton, "The other Side of the Closet: The Coming-Out Crisis for Straight Spouses and Families,” John Wiley and Sons, Inc., New York, 1994.

[5] S. S. Janus and C. L. Janus, "The Janus Report on Sexual Behavior,” Wiley, New York, 1993.

[6] M. W. Ross, “The Married Homosexual Man,” Routledge \& Kegan Paul, London, 1983.

[7] A. P. Buxton, "Paths and Pitfalls: How Heterosexual Spouses Cope When Their Husbands or Wives Come Out,” In: J. L. Wetchler and J. J. Binger, Eds., Relationship Therapy with Same-Sex Couples, Haworth Press, New York, 2004, pp. 95-109.

[8] D. J. Higgins, “Gay Men from Heterosexual Marriages: Attitudes, Behaviors, Childhood Experiences, and Reasons for Marriage,” Journal of Homosexuality, Vol. 42, No. 4, 2002, pp. 15-34.

[9] R. B. Lee, "Psychosocial Contexts of the Homosexuality of Filipino Men in Heterosexual Unions," Journal of Homosexuality, Vol. 42, No. 4, 2002, pp. 35-63.

[10] R. M. Berger, "Gay and Gray: The Older Homosexual Man,” University of Illinois Press, Urbana, 1982.

[11] E. Coleman, "Bisexual and Gay Men in Heterosexual Marriage: Conflicts and Resolutions in Therapy,” Journal of Homosexuality, Vol. 7, No. 2-3, 1982, pp. 93-103.

[12] E. Coleman, "Integration of Male Bisexuality and Marriage,” Journal of Homosexuality, Vol. 11, No. 1-2, 1985, pp. 189-207.

[13] D. R. Matteson, "Bisexual Men in Marriage: Is a Positive Homosexual Identity and Stable Marriage Possible?” Journal of Homosexuality, Vol. 11, No. 1-2, 1985, pp. 149-171.

[14] J. J. Binger, "Working with Gay Fathers: Developments, Postdivorce Parenting, and Therapeutic Issues,” In: J. Laird and R. J. Green, Eds., Lesbians and Gays in Couples and Families, Jossey-Bass, San Francisco, 1996, pp. 370-403.

[15] R. A. Isay, "Heterosexually Married Homosexual Men: Clinical and Developmental Issues,” American Journal of Orthopsychiatry, Vol. 68, No. 3, 1998, pp. 424-432.

[16] F. W. Bozett, Gay Fathers, “Gay and Lesbian Parents,” In: F. W. Bozett, Ed., Praeger, New York, 1987, pp. 3-22.

[17] Pennebaker, J. W. "Confession, Inhibition, and Disease," In: L. Berkowitz Ed., Advances in Experimental Social Psychology, Academic Press, New York, 1989, pp. 211244
[18] J. W. Pennebaker, "Emotion, Disclosure, and Health," American Psychological Association, Washington, 1995.

[19] I. H. Meyer, "Prejudice, Social Stress, and Mental Health in Lesbian, Gay, and Bisexual Populations: Conceptual Issues and Research Evidence," Psychological Bulletin, Vol. 129, No. 5, 2003, pp. 674-697.

[20] J. D. Latham and G. D. White, “Coping with Homosexual Expression within Heterosexual Marriage: Five Case Studies,” Journal of Sex \& Marital Therapy, Vol. 4, No. 3, 1978, pp. 198-212.

[21] M. A. Yarhouse and R. L. Seymore, "Intact Marriages in Which One Partner Disidentifies with Experiences of Same-Sex Attraction: A Follow-Up Study," The American Journal of Family Therapy, Vol. 34, 2006, pp. 151-161.

[22] J. W. Creswell, "Qualitative Inquiry and Research Design: Choosing among five Traditions,” Sage, Thousand Oaks, 1998.

[23] Y. S. Lincoln and E. G. Guba, "Naturalistic Inquiry," Sage, Beverly Hills, 1985.

[24] M. Q. Patton, "Qualitative Evaluation and Research Methods,” Sage, Newbury Park, 1990.

[25] N. K. Denzin and Y. S. Lincoln, "Handbook of Qualitative Research,” Sage, Thousand Oaks, 2000.

[26] C. E. Moustakas, "Phenomenological Research Methods,” Sage, Thousand Oaks, 1994.

[27] M. Barker, "Constructing a Polyamorous Identity in a Monogamous World,” Journal of Constructivist Psychology, Vol. 18, No. 1, 2005, pp. 75-88.

[28] S. Jackson, "Heterosexuality, Heteronormativity and Gender Hierarchy: Some Reflections on Recent Debates," In: J. Weeks, J. Holland and M. Waites, Eds., Sexualities and Society: A Reader, Polity Press, Cambridge, 2003, pp. 69-83.

[29] D. M. Anapol, "Polyamory: The New Love without Limits,” IntiNet Resource Center, San Rafael, 1997.

[30] R. A. Heinlein, "Stranger in a Strange Land,” Ace Books, New York, 1961.

[31] C. Klesse, "Polyamory and its 'Others': Contesting the Terms of Non-Monogamy,” Sexualities, Vol. 9, No. 5, 2006, pp. 565-583.

[32] M. Bettinger, "Polyamory and Gay Men: A Family Systems Approach,” In: J. J. Bigner, Ed., An Introduction To GLBT Family Studies, Haworth Press, New York, 2006, pp. 161-181.

[33] L. Jamieson, "Intimacy, Negotiated Non-Monogamy and the Limits of the Couple,” In: J. Ducombe, K. Harrison, G. Allan and D. Marsden, Eds., The State of Affair, NJ: Lawrence Erlbaum Associated, Mahwah, 2004, pp. 35-57.

[34] A. Ben-Ari, "The Discovery That an Offspring is Gay: Parents', Gay Men's, and Lesbians' Perspectives," Journal of Homosexuality, Vol. 30, No. 1, 1995, pp. 89-112. 